Article

\title{
Characteristics of Official Wheelchair Basketball Games in Hot and Temperate Conditions
}

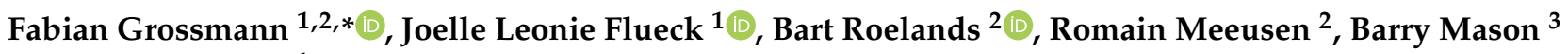 \\ and Claudio Perret ${ }^{1}$
}

check for

updates

Citation: Grossmann, F.; Flueck, J.L.; Roelands, B.; Meeusen, R.; Mason, B.; Perret, C. Characteristics of Official Wheelchair Basketball Games in Hot and Temperate Conditions. Int. J. Environ. Res. Public Health 2022, 19, 1250. https://doi.org/10.3390/ ijerph19031250

Academic Editors: Diego Muñoz Marín, Jesús Siquier Coll and Ignacio Bartolomé Bartolomé

Received: 20 December 2021

Accepted: 15 January 2022

Published: 23 January 2022

Publisher's Note: MDPI stays neutral with regard to jurisdictional claims in published maps and institutional affiliations.

Copyright: (c) 2022 by the authors. Licensee MDPI, Basel, Switzerland. This article is an open access article distributed under the terms and conditions of the Creative Commons Attribution (CC BY) license (https:// creativecommons.org/licenses/by/ $4.0 /)$.
1 Swiss Paraplegic Centre, Sports Medicine, 6207 Nottwil, Switzerland joelle.flueck@sportmedizin-nottwil.ch (J.L.F.); claudio.perret@paraplegie.ch (C.P.)

2 Human Physiology and Sports Physiotherapy Research Group, Vrije Universiteit Brussel, 1050 Brussels, Belgium; bart.roelands@vub.be (B.R.); romain.meeusen@vub.be (R.M.)

3 School of Sport, Exercise and Health Sciences, Loughborough University, Loughborough LE11 3TU, UK; barry.mason@gbwr.org.uk

* Correspondence: fabian.grossmann@paraplegie.ch

\begin{abstract}
This study compared performance parameters of two wheelchair basketball games under hot $\left(30.3{ }^{\circ} \mathrm{C}, 52 \%\right.$ relative humidity) and temperate $\left(21.6^{\circ} \mathrm{C}, 30 \%\right.$ relative humidity $)$ environmental conditions and described the characteristics of wheelchair basketball. Eight wheelchair basketball players from two teams were monitored during two games using an indoor position tracking system. Total distance, mean- and peak-speed, playing-time, number of sprints, sprints per minute, heart rate and rate of perceived exertion were recorded. Additionally, athletes with a lesion level above and below T6 were compared. No measured parameter differed between the games. Across quarters (Q) mean velocity $(\mathrm{m} / \mathrm{s})(\mathrm{Q} 1: 1.01 ; \mathrm{Q} 2: 1.10 ; \mathrm{Q} 3: 1.18 ; \mathrm{Q} 4: 1.06 ; p<0.001)$ and sprints per minute $(\mathrm{Q} 1: 16$; Q2: 14; Q3: 23; Q4: 14; $p=0.033$ ) differed significantly, independent of the conditions. Descriptive statistics did not reveal differences between the groups with a lesion level below or above T6. In the present study, hot environmental conditions seemed not to have an impact on activity parameters of wheelchair basketball players. It was speculated that the game intensity and therefore metabolic heat production was too low; consequently, the athletes had a sufficient heat loss to prevent a decrease in performance during the play in hot conditions.
\end{abstract}

Keywords: thermoregulation; heat stress; spinal cord injury; exercise

\section{Introduction}

Match and team performance in wheelchair basketball (WCB) are strongly influenced by the athletes' mobility performance, which is determined by the interaction of the athletes' physical performance and their wheelchair [1]. Physical performance is often quantified by means of oxygen uptake, heart rate (HR) and lactate production or drag force [2,3], whereas mobility performance is used to quantify the interaction of the athlete and his wheelchair in terms of acceleration, speed and covered distance $[1,4]$. Furthermore, activity profiles were used to describe the physical and energy demands of wheelchair team sports activities (i.e., WCB and wheelchair rugby) [5-7]. These demands, as well as the physical performance, might be influenced by external aspects such as the equipment (e.g., wheelchair, type of tires, tire pressure), floor type or environmental conditions (i.e., temperature, humidity) [8-10] and the status of personal heat acclimation as well [11]. WCB games are mostly played in air-conditioned sport facilities, which should provide uniform environmental conditions. However, not all facilities have an efficient air-conditioning system and therefore maintaining standard environmental conditions is difficult [12], and games in hot conditions $\left(>28^{\circ} \mathrm{C}\right)$ may be possible.

WCB is, among others, played by athletes with a traumatic spinal cord injury (SCI). As a consequence of the injury, the regulation of body core temperature is impaired among 
individuals with SCI [13]. This has been demonstrated to occur even during exercise in a cool ambient temperature, and it is further exacerbated during exercise in the heat [13]. The risk for heat-related illness and consequently a reduction in exercise performance is also elevated with increasing environmental temperature in athletes with SCI with a lesion level above T6 $[13,14]$. However, the effect of environmental heat stress on performance parameters and activity profiles has not been examined in an official game situation in wheelchair sports so far. Additionally, to date only a few studies published data on distance and speeds by WCB players during real gameplay [3,5,15-17] using different methodological approaches.

It has been shown that environmental conditions during exercise in able-bodied (AB) athletes trigger significant effects on the physiological responses during physical activity (i.e., increased HR, core temperature, sweat rate) [18]. Chmura, et al. [19] examined the performance of $\mathrm{AB}$ elite soccer players under different conditions. The most comfortable condition for physical exercise was at an air temperature below $22{ }^{\circ} \mathrm{C}$ and a relative humidity below $60 \%$ in this study. A temperature above $28{ }^{\circ} \mathrm{C}$ or $22{ }^{\circ} \mathrm{C}$ with a relative humidity $>60 \%$ led to decreased performance outcomes. Data from the same players showed that high environmental heat stress changed their activity patterns (i.e., reduced high-intensity activity, number of sprints) during matches [20]. In addition, research indicates that the challenges of hot environmental conditions in combination with exercise are complex and difficult to fully comprehend, as athletes are affected in different ways (e.g., heat exhaustion, muscle cramp, thermal discomfort) [21,22].

Hence, the present study aimed to compare performance outcomes of two official (friendly games, with official IWBF rules) WCB games, one under thermoneutral (TMP), a second under hot (HOT) conditions. It was hypothesized that due to the impaired thermoregulatory abilities of athletes with SCI, performance in HOT will be reduced (i.e., covered distance, number of sprints), and the activity patterns might change (i.e., less time in high-intensity but more in low-intensity speed zones).

\section{Materials and Methods}

\subsection{Participants}

In total, eight male WCB players volunteered to participate in the present investigation (Table 1). Two players played both games, the others in HOT or TMP, which resulted in five players per game. The detailed study design is presented in Figure 1. Inclusion criteria were age between 18 and 60 years, male, valid classification for WCB, member of a national team or in a team playing in Euro League and had a traumatic SCI. Athletes with an amputation, spina bifida or cerebral palsy were excluded. All participants were informed about the experimental protocol (orally and in writing), and all participants provided their written, informed consent prior to data collection. The study was approved by the local ethical committee (Ethikkommission Nordwest- und Zentralschweiz, Basel, Switzerland). All procedures were conducted according to the Helsinki Declaration [23].

Table 1. Participants' characteristics.

\begin{tabular}{cccccc}
\hline Subject & Age (years) & Lesion Level & Classification & Weight (kg) & Game Played \\
\hline 1 & 29.3 & L1 & 4.0 & 82.8 & HOT \\
2 & 39.7 & C5 & 2.5 & 94.6 & HOT, TMP \\
3 & 46.3 & T5 & 1.0 & 78.6 & HOT, TMP \\
4 & 40.2 & T4 & 1.0 & 83.0 & HOT \\
5 & 29.6 & T10 & 3.0 & 70 & HOT \\
6 & 42.4 & L1 & 4.0 & 110.6 & TMP \\
7 & 59.7 & T10 & 2.0 & 111.6 & TMP \\
8 & 20.0 & T8 & 1.0 & 74.2 & TMP \\
\hline $\begin{array}{l}\text { Median, } \\
\text { IQR }\end{array}$ & $40.0,13.2$ & - & & \\
IQR = interquartile range; HOT = game in hot conditions; TMP = game in temperate conditions; Classification \\
refers to IWBF Official Player Classification [24].
\end{tabular}


recruiting athletes

inclusion criteria:

$18-60$ years, traumatic $\mathrm{SCl}$

\author{
game in $\mathrm{HOT}, 30.3^{\circ} \mathrm{C}$ : \\ $\mathrm{n}=5$ \\ game in $\mathrm{TMP}, 21.6^{\circ} \mathrm{C}$ : \\ $n=5$
}

data analysis

$\mathrm{n}=10$ data sets,

5 HOT, 5 TMP,

$\mathrm{n}=2$ played both games

30 days between the games

Figure 1. Study design, $\mathrm{SCI}=$ spinal cord injury, $\mathrm{HOT}=$ hot conditions, $\mathrm{TMP}=$ temperate conditions, $\mathrm{n}=$ number of participants.

\subsection{Procedure}

Data were collected from two official WCB games (friendly games with official IWBF rules), played over four quarters of $10 \mathrm{~min}$ (effective time) on two separate days. Environmental conditions in HOT were $30.3{ }^{\circ} \mathrm{C}$ and $52 \%$ relative humidity and in TMP $21.6{ }^{\circ} \mathrm{C}$ and 30\% relative humidity (Irox JB913R, Electronic Thermo-Hygrometer, OS Technology AG, Guemligen, Switzerland). One hour before the game, athletes were again informed about the detailed procedure and equipped with a HR monitor (Acentas HerzfrequenzMonitoring Team System, Acentas GmbH, Hoergertshausen, Germany). A lightweight tag for position tracking was mounted on the wheelchair frame as close as possible to the pivot and point of rotation. Athletes performed their usual, individual pre-game warm-up with a duration of $15 \mathrm{~min}$ at a perceived exertion between 10 and 12 on the Borg-scale [25]. Data collection began with the start of the match clock and was paused during time-outs, breaks between quarters and when a player was on the bench. Immediately after the game, participants were asked to rate their perceived exertion on a Borg-scale from 6 to 20 [25]. Heart rate was measured with a sample rate of $1 \mathrm{~Hz}$. The recording was started with the beginning of the game. Playing time (PT) for each player was assessed by a commercially available digital stopwatch (Delta, Sport-Thieme AG, St. Gallen, Switzerland).

\subsection{Equipment/Location/Instruments}

Participants played in their own basketball-specific wheelchairs, which were weighed. Wheel diameter, camber angle were determined and type of tire and pressures were noted individually to guarantee uniformity in both games. Games were played in an indoor sports complex with a hardwood flooring, typical for indoor wheelchair team court sports. WCB court has the same dimensions as the court for AB basketball players $(28 \mathrm{~m} \times 15 \mathrm{~m})$. The sport hall was heated naturally. Environmental temperature and relative humidity were measured throughout (values were written down every 10th minute; mean was calculated at the end) with a thermo- and hygrometer and were constant during the game.

The ITS (XLOCATE, Axiamo, Biel, Switzerland) is a position tracking system based on ultra-wideband signals. Six wireless reference antennas were located around the playing field, one in each corner and two parallel to the halfway line to have an optimal court coverage. The tags mounted on wheelchairs emitted ultra-wideband signals and were tracked by means of time difference of arrival and triangulation. Tags were sampled at $20 \mathrm{~Hz}$ with a precision of $\pm 20 \mathrm{~cm}$. The fully mobile configuration was based on wireless technologies and battery-powered devices. The tags came in a small form factor and were lightweight (size $=50 \times 80 \times 9 \mathrm{~mm}$, weight $=30 \mathrm{~g})$. Raw data files were exported and filtered using a 3-pass sliding-average filter with a window width proportional to the tag frequency [26]. Afterwards, total distance in meters, mean velocity $\left(\mathrm{V}_{\text {mean }}, \mathrm{m} \cdot \mathrm{s}^{-1}\right)$, peak velocity $\left(\mathrm{V}_{\text {peak }}, \mathrm{m} \cdot \mathrm{s}^{-1}\right)$, number of sprints, number of sprints per min, PT and percentage of time spent in six different speed zones $(Z 1: 0.0-0.49 \mathrm{~m} / \mathrm{s}, \mathrm{Z2}: 0.5-0.99 \mathrm{~m} / \mathrm{s}, \mathrm{Z3}: 1.0-1.49 \mathrm{~m} / \mathrm{s}$, Z4: $1.5-1.99 \mathrm{~m} / \mathrm{s}$, Z5: $2.0-2.49 \mathrm{~m} / \mathrm{s}, \mathrm{Z6}:>2.5 \mathrm{~m} / \mathrm{s})$ were calculated. A sprint was defined when velocity was larger than two meters per second on a duration longer than two seconds. The $\mathrm{Z}$ were adopted from wheelchair rugby [27]. 


\subsection{Statistics}

Data were analyzed using the software $\mathrm{R}$ ( $\mathrm{R}$ Foundation for Statistical Computing version 3.6.0; Vienna, Austria). After checking all measured parameters for normality using Shapiro-Wilk's tests, median and interquartile range (IQR) were calculated for all parameters. Due to nomparametric data, mean differences between both games were explored using Wilcoxon's signed rank tests. To detect significant changes over the course of the four quarters the Brunner-Munzel Test [28] was used. Wilcoxon's signed-rank test with Bonferroni $p$-level adjustment was used as post hoc test. Sample size estimation using G*Power software (v.3.1.9.2, Franz Faul, Kiel, Germany) [29] with the assumption of a significant difference in $\mathrm{V}_{\text {mean }}$ of $0.15 \mathrm{~m} / \mathrm{s} \pm 0.07 \mathrm{~m} / \mathrm{s}$ revealed a power of $>80 \%$ with 5 study participants per game. The results were evaluated within a $95 \%$ confidence interval and at a statistical significance level of $p<0.05$. Additionally, data were split up to above and below lesion level T6 and are presented in median.

\section{Results}

\subsection{HOT vs. TMP}

Activity patterns did not differ between HOT and TMP (Table 2). Time spent in different $Z$ did not differ between the two games (Table 3). Descriptive statistics did reveal remarkable differences in covered distance, total sprints, $V_{\text {peak }}$ and PT between players with a lesion level above and below T6 (Tables 4 and 5).

Table 2. Activity patterns of two wheelchair basketball games, one in hot and one in temperate environmental conditions.

\begin{tabular}{|c|c|c|c|c|c|c|c|}
\hline \multirow[b]{2}{*}{ Measured Parameter } & \multicolumn{2}{|c|}{ HOT } & \multicolumn{2}{|c|}{ TMP } & \multicolumn{2}{|c|}{ HOT and TMP Merged } & \multirow{2}{*}{$\begin{array}{c}\text { Difference HOT } \\
\text { vs. TMP } \\
p\end{array}$} \\
\hline & Median & IQR & Median & IQR & Median & IQR & \\
\hline Total distance $[\mathrm{m}]$ & 3286.7 & 1906.8 & 3477.6 & 1458.2 & 3332.0 & 1853.6 & 0.31 \\
\hline $\mathrm{V}_{\text {mean }}\left[\mathrm{m} \cdot \mathrm{s}^{-1}\right]$ & 1.12 & 0.1 & 1.07 & 0.1 & 1.1 & 0.1 & 0.54 \\
\hline $\mathrm{V}_{\text {peak }}\left[\mathrm{m} \cdot \mathrm{s}^{-1}\right]$ & 4.15 & 0.91 & 4.12 & 0.35 & 4.14 & 0.5 & 0.69 \\
\hline Number of sprints & 89 & 61 & 68 & 30 & 68 & 53 & 1.00 \\
\hline $\begin{array}{l}\text { Relative sprints } \\
\text { [sprint/min] }\end{array}$ & 1.5 & 0.4 & 1.0 & 0.3 & 1.2 & 0.4 & 0.22 \\
\hline PT [min] & 54.8 & 27.0 & 69.4 & 35.6 & 58.0 & 33.0 & 0.31 \\
\hline $\mathrm{HR}_{\text {mean }}[\mathrm{bpm}]$ & 122 & 22 & 116 & 7 & 118 & 22 & 0.42 \\
\hline $\mathrm{HR}_{\max }[\mathrm{bpm}]$ & 173 & 7 & 144 & 5 & 156 & 32 & 0.42 \\
\hline RPE [Borg] & 15 & 2 & 15 & 1 & 15 & 0.75 & 0.21 \\
\hline \multicolumn{8}{|c|}{$\begin{array}{l}\mathrm{HOT}=\text { game in hot conditions; } \mathrm{TMP}=\text { game in temperate conditions; } \mathrm{V}_{\text {mean }}=\text { mean velocity; } \mathrm{V}_{\text {peak }}=\text { peak } \\
\text { velocity; } \mathrm{PT}=\text { playing time; } \mathrm{HR}_{\max }=\text { maximal heart rate; } \mathrm{HR}_{\text {mean }}=\text { mean heart rate; } \mathrm{IQR}=\text { inter quartile range; } \\
p=p \text {-value. } \\
\text { Table 3. Percentage of time spent in different speed zones of two wheelchair basketball games, one in } \\
\text { hot and one in temperate environmental conditions. }\end{array}$} \\
\hline & \multicolumn{2}{|c|}{ HOT } & \multicolumn{2}{|c|}{ TMP } & \multicolumn{2}{|c|}{ HOT and TMP Merged } & $\begin{array}{c}\text { Difference HOT } \\
\text { vs. TMP }\end{array}$ \\
\hline Measured Parameter & Median & IQR & Median & IQR & Median & IQR & $p$ \\
\hline $\mathrm{Z} 10.0-0.49 \mathrm{~m} \cdot \mathrm{s}^{-1}[\%]$ & 39.4 & 8.5 & 48.2 & 6.8 & 43.7 & 8.2 & 0.09 \\
\hline $\mathrm{Z} 20.5-0.99 \mathrm{~m} \cdot \mathrm{s}^{-1}[\%]$ & 40.7 & 5.2 & 34.4 & 7.5 & 37.2 & 6.9 & 0.15 \\
\hline Z3 $1.0-1.49 \mathrm{~m} \cdot \mathrm{s}^{-1}[\%]$ & 12.2 & 1.9 & 13.1 & 1.7 & 12.3 & 1.5 & 0.84 \\
\hline $\mathrm{Z} 41.5-1.99 \mathrm{~m} \cdot \mathrm{s}^{-1}[\%]$ & 4.2 & 1.1 & 3.5 & 5.2 & 3.7 & 0.8 & 0.31 \\
\hline Z5 $2.0-2.49 \mathrm{~m} \cdot \mathrm{s}^{-1}[\%]$ & 2.4 & 0.6 & 1.7 & 0.5 & 2.0 & 0.9 & 0.31 \\
\hline $\mathrm{Z} 6>2.5 \mathrm{~m} \cdot \mathrm{s}^{-1}[\%]$ & 0.8 & 1.2 & 0.5 & 0.6 & 0.6 & 0.9 & 0.31 \\
\hline
\end{tabular}


Table 4. Comparison of players with a lesion level above and below T6.

\begin{tabular}{|c|c|c|c|c|c|c|}
\hline \multirow[b]{2}{*}{ Measured Parameter } & \multicolumn{2}{|c|}{ HOT } & \multicolumn{2}{|c|}{ TMP } & \multicolumn{2}{|c|}{$\begin{array}{l}\text { Differences between } \\
\text { Lesion Levels }\end{array}$} \\
\hline & $\begin{array}{l}\text { Above } \\
\text { T6 }\end{array}$ & $\begin{array}{l}\text { Below } \\
\text { T6 }\end{array}$ & $\begin{array}{l}\text { Above } \\
\text { T6 }\end{array}$ & $\begin{array}{l}\text { Below } \\
\text { T6 }\end{array}$ & HOT & TMP \\
\hline Total distance [m] & 1470 & 3368 & 3582 & 2057 & -1898 & 1525 \\
\hline $\mathrm{V}_{\text {mean }}\left[\mathrm{m} \cdot \mathrm{s}^{-1}\right]$ & 1.11 & 1.22 & 1.04 & 1.12 & -0.11 & -0.08 \\
\hline $\mathrm{V}_{\text {peak }}\left[\mathrm{m} \cdot \mathrm{s}^{-1}\right]$ & 3.9 & 4.95 & 4.28 & 4.12 & -1.05 & 0.16 \\
\hline Number of sprints & 30 & 92 & 68 & 38 & -62 & 30 \\
\hline $\begin{array}{l}\text { relative sprint } \\
\text { [sprint/min] }\end{array}$ & 1.2 & 1.8 & 0.9 & 1.3 & -0.6 & -0.4 \\
\hline $\mathrm{PT}[\mathrm{min}]$ & 34.3 & 58.0 & 73.8 & 35.6 & -23.7 & 38.2 \\
\hline $\mathrm{HR}_{\text {mean }}[\mathrm{bpm}]$ & 118 & 147 & 127 & 116 & -29 & 11 \\
\hline $\mathrm{HR}_{\max }[\mathrm{bpm}]$ & 167 & 179 & 152 & 144 & -12 & 8 \\
\hline RPE [Borg] & 13 & 16 & 16 & 15 & -3 & 1 \\
\hline
\end{tabular}

HOT = game in hot conditions; TMP = game in temperate conditions; $\mathrm{V}_{\text {mean }}=$ mean velocity; $\mathrm{V}_{\text {peak }}=$ peak velocity; $\mathrm{PT}=$ playing time; $\mathrm{HR}_{\max }=$ maximal heart rate; $\mathrm{HR}_{\text {mean }}=$ mean heart rate.

Table 5. Comparison of time spent in different speed zones of players with a lesion level above and below T6.

\begin{tabular}{|c|c|c|c|c|c|c|}
\hline \multirow[b]{2}{*}{ Measured Parameter } & \multicolumn{2}{|c|}{ HOT } & \multicolumn{2}{|c|}{ TMP } & \multicolumn{2}{|c|}{$\begin{array}{l}\text { Difference between } \\
\text { Lesion Levels }\end{array}$} \\
\hline & $\begin{array}{l}\text { Above } \\
\text { T6 }\end{array}$ & $\begin{array}{l}\text { Below } \\
\text { T6 }\end{array}$ & $\begin{array}{l}\text { Above } \\
\text { T6 }\end{array}$ & $\begin{array}{l}\text { Below } \\
\text { T6 }\end{array}$ & HOT & TMP \\
\hline $\mathrm{Z} 10.0-0.49 \mathrm{~m} \cdot \mathrm{s}^{-1}[\%]$ & 39.4 & 39.4 & 44.6 & 48.2 & -5.2 & -8.8 \\
\hline $\mathrm{Z} 20.5-0.99 \mathrm{~m} \cdot \mathrm{s}^{-1}[\%]$ & 37.6 & 40.7 & 36.5 & 31.1 & 1.1 & 9.6 \\
\hline Z3 $1.0-1.49 \mathrm{~m} \cdot \mathrm{s}^{-1}[\%]$ & 14.1 & 12.1 & 13.3 & 13.1 & 0.8 & -1 \\
\hline Z4 $1.5-1.99 \mathrm{~m} \cdot \mathrm{s}^{-1}[\%]$ & 3.9 & 4.7 & 3.1 & 3.9 & 0.8 & 0.8 \\
\hline Z5 $2.0-2.49 \mathrm{~m} \cdot \mathrm{s}^{-1}[\%]$ & 2.7 & 2.1 & 1.5 & 1.9 & 1.2 & 0.2 \\
\hline $\mathrm{Z} 6>2.5 \mathrm{~m} \cdot \mathrm{s}^{-1}[\%]$ & 2.0 & 0.5 & 0.6 & 0.5 & 1.4 & 0 \\
\hline
\end{tabular}

$\mathrm{HOT}=$ game in hot conditions; TMP = game in temperate conditions; $\mathrm{Z}=$ speed zone.

\subsection{HOT and TMP (Overall Data)}

Across the quarters, $\mathrm{V}_{\text {mean }}(p<0.001)$ and number of sprints per minute $(p=0.033)$ differed significantly. In quarter $1(\mathrm{Q} 1), \mathrm{V}_{\text {mean }}$ was significantly lower compared with quarter $3(\mathrm{Q} 3)(p=0.031)$, and the number of sprints per minute was significantly smaller in quarter $2(\mathrm{Q} 2)$ compared with Q3 $(p=0.042)$. Total distance $(p=0.766), \mathrm{V}_{\text {peak }}(p=0.776)$, PT $(p=0.294)$, number of sprints $(p=0.801), \operatorname{HR}_{\max }(p=0.605)$ and $\mathrm{HR}_{\text {mean }}(p=0.355) \mathrm{did}$ not differ across quarters (Figure 2).

\subsection{Speed Zones}

Percentage of time spent in six different speed zones (Z1-Z6) differed significantly across the zones $(p<0.001)$. Athletes spent significantly more time in $Z 1$ compared with Z3-Z6 (for all differences: $p<0.001$ ), significantly more time in Z2 compared with Z3-Z6 (for all differences: $p<0.001$ ), significantly more time in Z3 compared with Z4-Z6 (for all differences: $p<0.001$ ), significantly more time in Z4 compared with Z5 and Z6 (for both differences, $p<0.001)$ and significantly more time in Z5 compared with Z6 ( $p=0.002)$ (Figure 3). 

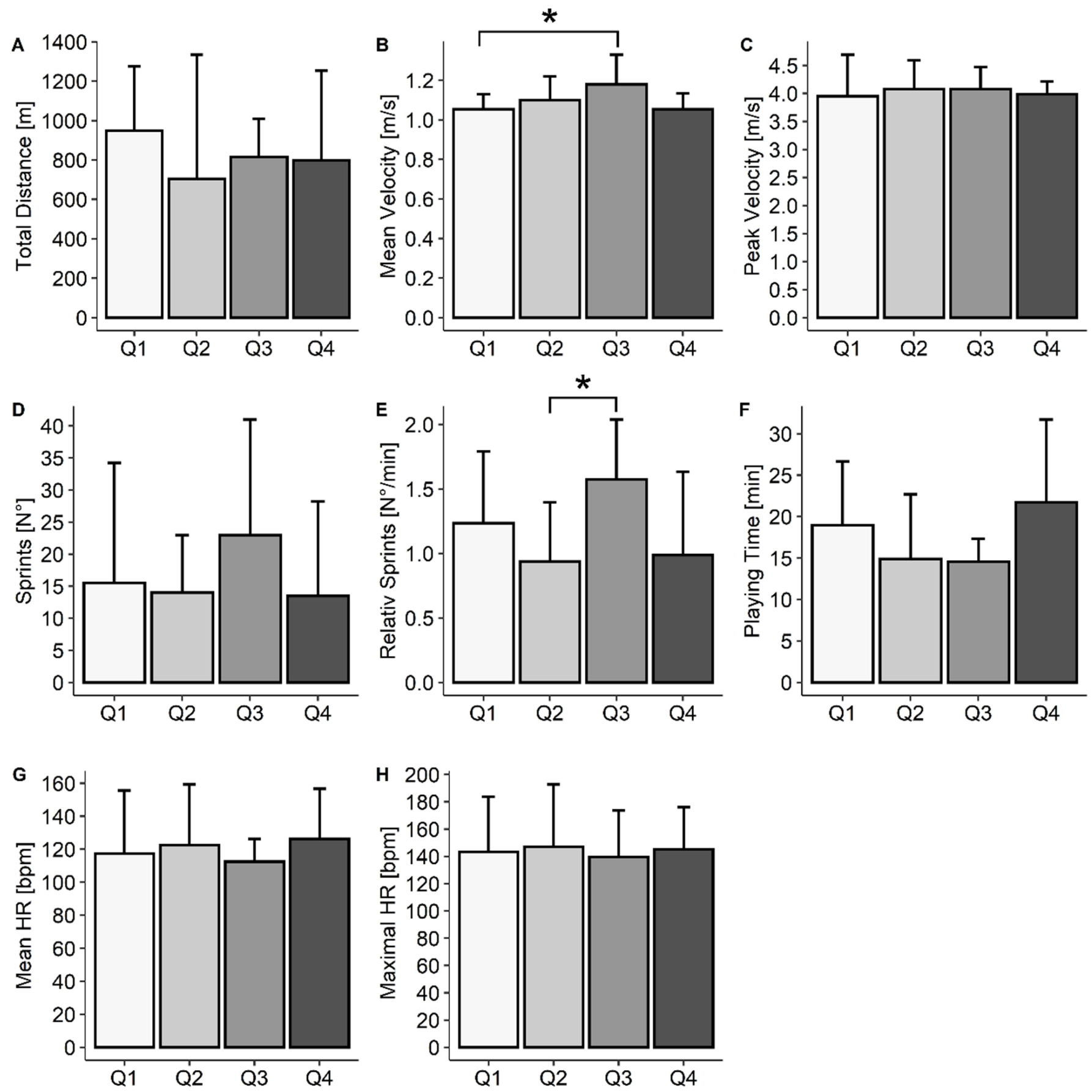

Figure 2. Overall data presented in median \pm interquartile range (IQR), total distance (A), mean velocity (B), peak velocity $(\mathbf{C})$, number of sprints (D), sprints per minute $(\mathbf{E})$, playing time $(\mathbf{F})$, mean heart rate $(\mathbf{G})$, maximal heart rate $(\mathbf{H})$ during each quarter $(\mathbf{Q}),{ }^{*}$ Significant difference $(\mathbf{B}), p=0.0312$; (E), $p=0.063)$. 


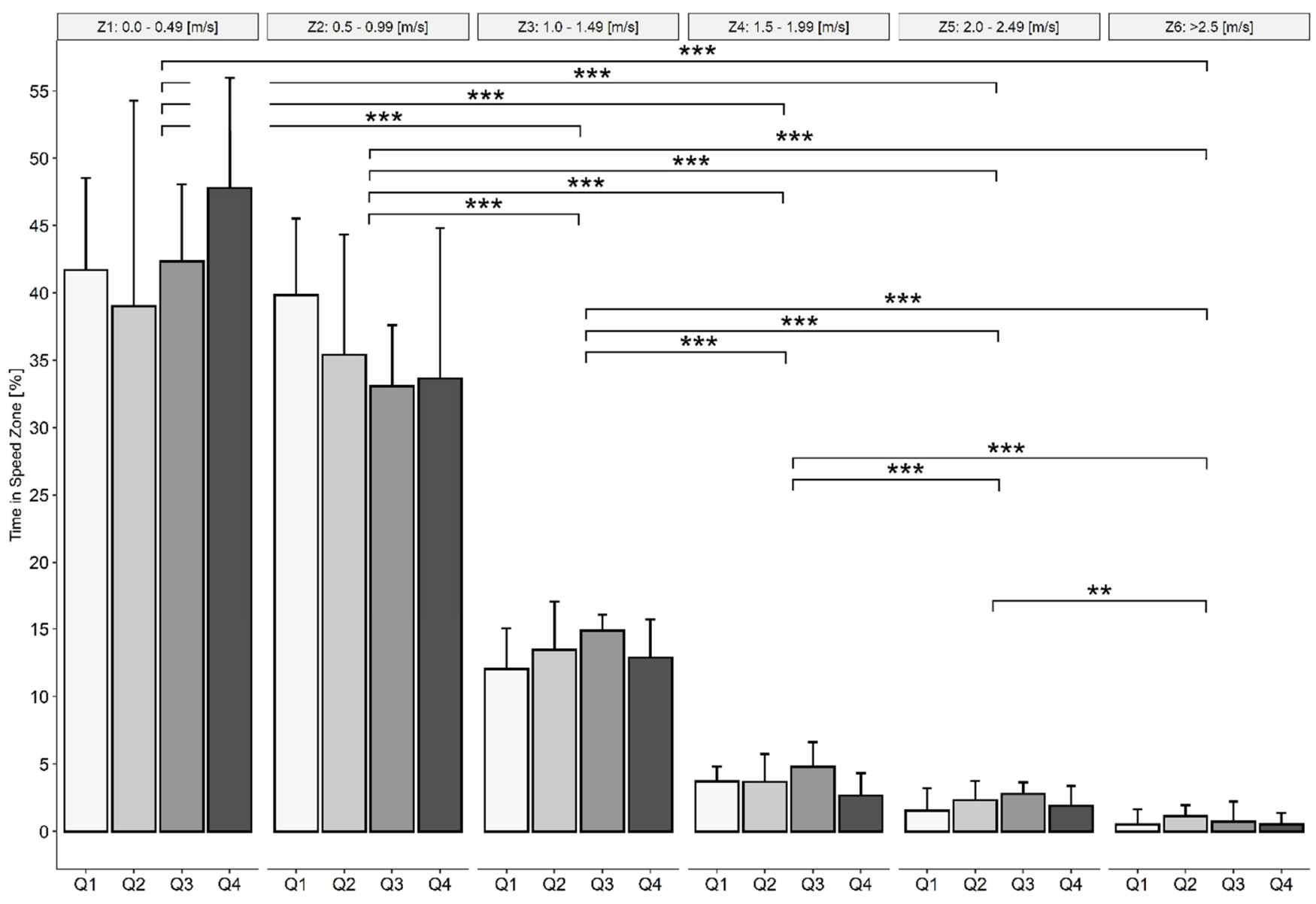

Figure 3. Percentage of time spent in different speed zones (Z), median \pm interquartile range (IQR), *** significantly different from other zones $(p<0.001),{ }^{* *}$ significantly different from other speed zone $(p=0.002)$.

\section{Discussion}

The present study was the first to analyze the effect of environmental heat stress on performance parameters and activity profiles in an official WCB game and to compare these parameters with an official game under temperate conditions. The results showed that playing WCB under hot or temperate conditions seemed not to affect the performance of WCB players in the present study.

\subsection{Comparison of HOT and TMP}

The current study demonstrates that activity parameters such as total distance, $\mathrm{V}_{\text {mean }}$ $\mathrm{V}_{\text {peak }}$, number of sprints, number of sprints per min, PT and time in different speed zones, as well as HR and rating of perceived exertion, did not significantly differ between the games. Because this is the only study in wheelchair team sports so far, the comparison of hot and temperate conditions on the performance of individuals with SCI with other data is not possible.

In $\mathrm{AB}$, it was observed that hot environmental conditions seem to influence the activity patterns (i.e., reduced high-intensity activity, total distance) [20]. As a result of the loss of vasomotor control and the absence of sweating response below the lesion level in individuals with a SCI (the sympathetic innervation of the eccrine sweat glands exits the spinal cord at T1-L2) [30,31], it has to be noted that the impairment of the thermal and thermoregulatory responses depends on the level of the lesion and the completeness of the spinal rupture [13]. Therefore, it can be expected that the performance of players with a low-level lesion would not be affected by the same amount as in cases of athletes with a 
high-level lesion. Nevertheless, if an AB game is affected by reason of heat strain, at least the same would be expected for an SCI game, but this could not be observed in the present study. Players spent over $70 \%$ of the time in the lowest Z1 and Z2. It has been shown in the past that low intensity exercise is related to a small metabolic heat production [32]. Therefore, it is suggested that the stored heat in the body was not high enough to get overheated and affect performance. Thus, the ability to lose heat was still adequate and therefore performance was not influenced negatively. It can be argued that low lesion level players with a lesion below $\mathrm{T} 6$ are able to thermoregulate their body similar to AB. Players with a high lesion level (i.e., above T6) are associated with considerably worse thermoregulation [13]. Hence, it makes sense to take a closer look at players with a lesion level above and below T6 (Tables 4 and 5). The numbers reveal some remarkable differences but without a concrete direction that would allow a conclusion. Due to the small number of participants and large differences between the single subject, no clear pattern can be shown. Again, the above-mentioned low metabolic heat production can be used as an argument as well. The low-intensity during the game did not trigger a sufficient heat production to provoke differences between these two groups.

\subsection{Performance Characteristics during WCB Game}

Since no difference was found between the two conditions, the two games were analyzed together to provide data on the characteristics of WCB. It seems noteworthy that this was the first time that data were provided separated in quarters. Whereas total distance, $\mathrm{V}_{\text {peak }}, \mathrm{PT}$, number of sprints, maximal and mean HR did not differ across quarters, number of sprints per minute and $V_{\text {mean }}$ significantly differed across the quarters (Figure 1 ). Despite these differences, there was no clear pattern to determine which specific quarter revealed to be the one with the strongest performance (i.e., highest $V_{\text {mean }}$, highest number of sprints, highest mean HR).

The descriptive WCB data provide quantification of activity and performance during a game. Total distance, $\mathrm{V}_{\text {mean }}, \mathrm{V}_{\text {peak }}$, number of sprints, $\mathrm{PT}$, time in different speed zones, rate of perceived exertion and HR of two games were described. The finding differs in several parameters from the existing literature. Coutts [3] $\left(1.98 \mathrm{~m} \cdot \mathrm{s}^{-1}\right)$, Sporner et al. [5] $\left(1.48 \mathrm{~m} \cdot \mathrm{s}^{-1}\right)$ and Mason et al. [15] $\left(1.56 \mathrm{~m} \cdot \mathrm{s}^{-1}\right)$ presented notably higher $\mathrm{V}_{\text {mean }}$ values than presented in the current work $\left(1.10 \mathrm{~m} \cdot \mathrm{s}^{-1}\right)$. Coutts [3] found similar values for $V_{\text {peak }}\left(4.04 \mathrm{~m} \cdot \mathrm{s}^{-1}\right)$, whereas Mason et al. [15] found slightly higher values $\left(4.69 \mathrm{~m} \cdot \mathrm{s}^{-1}\right)$. Comparing total distance, each study had completely different findings. The large differences can mainly be explained by the different methods of collecting data. Coutts [3] only analyzed a portion of 6 min of an exhibition game, and values were collected with a magnetic reed switch mounted together with a laptop computer on the wheelchair, at which it is unclear when data collection was paused. Therefore, it is unclear whether data on moving during timeouts or calls by the referee were collected. Mason et al. [15] used a radio frequencybased indoor tracking system [26] and paused the collection during extended stoppages (e.g., timeouts, equipment calls). In the present study, the collection was only paused during timeouts. These differences in tracking modalities can lead to a difference in collected distance and thus a wrong calculation of $\mathrm{V}_{\text {mean }}$. Another aspect is the PT. Mason et al. [15] indicated a mean PT of 20:23 min, while in the present study 58:00 min were recorded. It is suggested that the longer the PT, the more weight is given to interruptions (e.g., calls by the referee) in the calculation of the various values.

\subsection{Speed Zones}

Taking a closer look at the distribution of the percentage of PT in different $Z$ unveils that $40 \%$ of the PT the players was spent in Z1, around $35 \%$ in $\mathrm{Z} 2$ and $13 \%$ in $\mathrm{Z} 3$. The athletes spent in total more than $80 \%$ of the PT between standstill and a velocity of $1.5 \mathrm{~m} \cdot \mathrm{s}^{-1}$. This is nearly 25\% more than Mason et al. [15] have observed. It is suggested that less participation time can lead to an increased intensity, and therefore the recorded values such as $V_{\text {mean }}$ must be higher. This matches with the measured HR values. Whereas 
Mason et al. [15] and Croft et al. [33] described a mean HR of around 155 beats per minute, the present study reported a value of 118 beat per minute, which is associated with a much lower exercise intensity. Since some athletes with SCI may have a disturbed HR regulation [34], and in other studies often other disabled athletes were included without SCI, this comparison has to be taken with caution.

When comparing $\mathrm{Z}$ with other wheelchair court sports, the level of performance matches with that of rugby (i.e., similar $V_{\text {mean }}$ ) [6]. Nevertheless, this does not match with the earlier investigation that reveals WCB as the sport with the highest performance (i.e., lower time spent in low-intensity zones) and rugby the one with the lowest [35]. It should be noted that the difference might be due to the use of different tracking systems, and therefore the findings by van der Slikke et al. [4] (activity profile of WCB) should be given more weight, as the different sports were measured with the same tracking tool.

\subsection{Limitations}

The recruitment of an appropriate number of participants is difficult since athletes with SCI represent a small group in the general population. The few participants included in this study, different participants under different conditions and a combination of athletes with a lesion level above and below T6 leads to a low power and therewith, the chance of detecting a true error. The chance that significant results reflect a true effect are decreased, and therefore an overestimation of the effect sizes is common [36]. Therefore, there needs to be a careful balance between not overrating significant findings and devaluing insignificant results. Another problematic issue is that each game of WCB has its own character. The two teams competing (i.e., different opponents), the team tactics, number of substitutions, field position of the players, the calls of the referees, or numbers of interruptions (i.e., timeouts, equipment calls) are important factors, which make a comparison of two games very difficult. Grouping athletes based on the lesion level also means selecting athletes with different playing-position and therefore different roles on court, which can lead to completely different performance parameters [1]. Due to the lack of prior research on the topic, the findings cannot be verified. Thus, field tests, which mimic WCB games, are necessary to conduct "games" under standardized conditions to compare physiological parameters between different conditions or between different lesion levels.

Comparing the merged data of both games with the existing literature $[3,5,15]$, remarkable differences in $\mathrm{V}_{\text {mean }}$ or PT are depicted. It is suggested that this disparity can also be a methodological issue. First, $\mathrm{V}_{\text {mean }}$ depends on the way it was calculated (i.e., covered distance divided by the overall time or active game time). Second, to collect the data, different tracking systems were used, which may not record data in the same way (i.e., different sensors, different sensor placements at the wheelchair, different recording protocols). Therefore, a guideline for the use of tracking systems, with information about the data collection process (i.e., when has the data collection to be paused) and the filtering of the data would be very useful. This would make the different systems more comparable and therefore the outcome data as well. Additionally, the development of a field test, which mimics the game as closely as possible, is essential and should be a further direction of research.

\subsection{Practical Applications}

Even if the generated data during both WCB games did not provide significant differences, the findings suggest that hot environmental conditions in WCB do not seem to be a major problem for individuals with a SCI. Nevertheless, it has to be considered that players with high-level lesions have impaired thermoregulatory functions and need more attention in future research. The characteristics of WCB change by nature from game to game. Therefore, for a better comparability of two environmental conditions, it is, on the one hand recommended to develop a field test that mimics the real games, and, on the other hand to investigate the variance in game performance as seen in AB soccer [37]. Only then would it be possible to make any suggestions and assignments on how to train and 
play under hot conditions. Finally, the market for tracking devices is growing rapidly and the tracking of indoor wheelchair sports activities is becoming easier and easier. However, the more tools that are available, the more difficult the comparison becomes. Thus, it is important to provide guidelines that point out the important determinants of collecting data with a tracking device.

\section{Conclusions}

In conclusion, this study demonstrated that a competitive WCB game in HOT seems not to have a different outcome regarding activity parameters compared with a game in TMP. Our finding suggests that overall intensity during these specific games was too low, and thus it is speculated that the produced metabolic heat was too low. Consequently, the athletes had sufficient heat loss, and performance was not degraded. The current setup included too many variables that could affect the outcome. Therefore, for future research, it would be a good to reduce the number of variables by first testing in a more standardized match such as a field test with maximal performance. If that reveals differences, a next step would be to test it in a more ecologically valid match setting.

Author Contributions: Conception and idea, F.G., J.L.F., C.P., B.R. and R.M.; data collection, F.G., J.L.F., C.P. and B.M.; data analysis, F.G.; draft manuscript preparation, F.G., with input from all authors; all authors reviewed the results and approved the final version of the manuscript; supervising, B.R., R.M., J.L.F. and C.P. All authors have read and agreed to the published version of the manuscript.

Funding: This research received no external funding.

Institutional Review Board Statement: The study was conducted in accordance with the Declaration of Helsinki, and the study was approved by Ethics Committee of Ethikkommission Nordwest- und Zentralschweiz, Basel, Switzerland (Approval-Nr.: 2018-01792, 19 October 2018).

Informed Consent Statement: Informed consent was obtained from all subjects involved in the study.

Data Availability Statement: The datasets used and analyzed during the current study are available from the corresponding author on reasonable request.

Acknowledgments: The authors would like to acknowledge financial support by Sports Medicine of the Swiss Paraplegic Centre and Swiss Olympic. We would also like to further acknowledge the assistance of Nicolas Hausammann, the Coach of the Swiss Wheelchair Basketball National Team, along with all the game organizers for their assistance and support. Appreciation is also extended to Selin Scherrer and Belinda Ruettimann for their assistance with data collection and to all the coaches and athletes who agreed to participate in this study.

Conflicts of Interest: The authors declare no conflict of interest.

\section{References}

1. de Witte, A.M.; Hoozemans, M.J.; Berger, M.A.; van der Woude, L.H.; Veeger, D.H. Do field position and playing standard influence athlete performance in wheelchair basketball? J. Sports Sci. 2016, 34, 811-820. [CrossRef]

2. Bloxham, L.A.; Bell, G.J.; Bhambhani, Y.; Steadward, R.D. Time Motion Analysis and Physiological Profile of Canadian World Cup Wheelchair Basketball Players. Sports Med. Train. Rehabil. 2001, 10, 183-198. [CrossRef]

3. Coutts, K.D. Dynamics of wheelchair basketball. Med. Sci. Sports Exerc. 1992, 24, 231-234. [CrossRef] [PubMed]

4. $\quad$ van der Slikke, R.M.A.; Berger, M.A.M.; Bregman, D.J.J.; Veeger, D.H.E.J. Wearable Wheelchair Mobility Performance Measurement in Basketball, Rugby, and Tennis: Lessons for Classification and Training. Sensors 2020, 20, 3518. [CrossRef]

5. Sporner, M.L.; Grindle, G.G.; Kelleher, A.; Teodorski, E.E.; Cooper, R.; Cooper, R.A. Quantification of Activity During Wheelchair Basketball and Rugby at the National Veterans Wheelchair Games: A Pilot Study. Prosthet. Orthot. Int. 2009, 33, $210-217$. [CrossRef]

6. $\quad$ Rhodes, J.; Mason, B.S.; Perrat, B.; Smith, M.J.; Malone, L.A.; Goosey-Tolfrey, V.L. Activity profiles of elite wheelchair rugby players during competition. Int. J. Sports Physiol. Perform. 2015, 10, 318-324. [CrossRef] [PubMed]

7. Griggs, K.E.; Havenith, G.; Price, M.J.; Mason, B.S.; Goosey-Tolfrey, V.L. Thermoregulatory responses during competitive wheelchair rugby match play. Int. J. Sports Med. 2017, 38, 177-183. [CrossRef]

8. de Groot, S.; Vegter, R.J.; van der Woude, L.H. Effect of wheelchair mass, tire type and tire pressure on physical strain and wheelchair propulsion technique. Med. Eng. Phys. 2013, 35, 1476-1482. [CrossRef] 
9. $\quad$ Ozgünen, K.T.; Kurdak, S.S.; Maughan, R.J.; Zeren, C.; Korkmaz, S.; Yazici, Z.; Ersöz, G.; Shirreffs, S.M.; Binnet, M.S.; Dvorak, J. Effect of hot environmental conditions on physical activity patterns and temperature response of football players. Scand. J. Med. Sci. Sports 2010, 20 (Suppl. S3), 140-147. [CrossRef]

10. Konefał, M.; Chmura, P.; Zacharko, M.; Baranowski, J.; Andrzejewski, M.; Błażejczyk, K.; Chmura, J. The influence of thermal stress on the physical and technical activities of soccer players: Lessons from the 2018 FIFA World Cup in Russia. Int. J. Biometeorol. 2021, 65, 1291-1298. [CrossRef] [PubMed]

11. Daanen, H.A.M.; Racinais, S.; Périard, J.D. Heat Acclimation Decay and Re-Induction: A Systematic Review and Meta-Analysis Sports Med. 2018, 48, 409-430. [CrossRef] [PubMed]

12. Fantozzi, F.; Lamberti, G. Determination of Thermal Comfort in Indoor Sport Facilities Located in Moderate Environments: An Overview. Atmosphere 2019, 10, 769. [CrossRef]

13. Grossmann, F.; Flueck, J.L.; Perret, C.; Meeusen, R.; Roelands, B. The Thermoregulatory and Thermal Responses of Individuals with a Spinal Cord Injury During Exercise, Acclimation and by Using Cooling Strategies-A Systematic Review. Front. Physiol. 2021, 12, 636997. [CrossRef] [PubMed]

14. Griggs, K.E.; Stephenson, B.T.; Price, M.J.; Goosey-Tolfrey, V.L. Heat-related issues and practical applications for Paralympic athletes at Tokyo 2020. Temperature 2019, 7, 37-57. [CrossRef] [PubMed]

15. Mason, B.S.; van der Slikke, R.M.A.; Hutchinson, M.J.; Berger, M.A.M.; Goosey-Tolfrey, V.L. The Effect of Small-Sided Game Formats on Physical and Technical Performance in Wheelchair Basketball. Int. J. Sports Physiol. Perform. 2018, 13, 891-896. [CrossRef] [PubMed]

16. van der Slikke, R.M.A.; Berger, M.A.M.; Bregman, D.J.J.; Veeger, H.E.J. From big data to rich data: The key features of athlete wheelchair mobility performance. J. Biomech. 2016, 49, 3340-3346. [CrossRef] [PubMed]

17. van der Slikke, R.M.A.; Mason, B.S.; Berger, M.A.M.; Goosey-Tolfrey, V.L. Speed profiles in wheelchair court sports; comparison of two methods for measuring wheelchair mobility performance. J. Biomech. 2017, 65, 221-225. [CrossRef]

18. Drust, B.; Atkinson, G.; Reilly, T. Future perspectives in the evaluation of the physiological demands of soccer. Sports Med. 2007, 37, 783-805. [CrossRef]

19. Chmura, P.; Konefał, M.; Andrzejewski, M.; Kosowski, J.; Rokita, A.; Chmura, J. Physical activity profile of 2014 FIFA World Cup players, with regard to different ranges of air temperature and relative humidity. Int. J. Biometeorol. 2017, 61, 677-684. [CrossRef]

20. Nassis, G.P.; Brito, J.; Dvorak, J.; Chalabi, H.; Racinais, S. The association of environmental heat stress with performance: Analysis of the 2014 FIFA World Cup Brazil. Br. J. Sports Med. 2015, 49, 609-613. [CrossRef] [PubMed]

21. Armstrong, L.E.; Casa, D.J.; Millard-Stafford, M.; Moran, D.S.; Pyne, S.W.; Roberts, W.O. American College of Sports Medicine position stand. Exertional heat illness during training and competition. Med. Sci. Sports Exerc. 2007, 39, 556-572. [CrossRef] [PubMed]

22. Roberts, W.O.; Armstrong, L.E.; Sawka, M.N.; Yeargin, S.W.; Heled, Y.; O'Connor, F.G. ACSM Expert Consensus Statement on Exertional Heat Illness: Recognition, Management, and Return to Activity. Curr. Sports Med. Rep. 2021, 20, 470-484. [CrossRef] [PubMed]

23. World Medical Association Declaration of Helsinki: Ethical principles for medical research involving human subjects. JAMA 2013, 310, 2191-2194. [CrossRef] [PubMed]

24. IWBF Player Classification Commission. IWBF, Official Player Classification Manual; IWBF: Mies, Switzerland, 2021.

25. Borg, G.A. Psychophysical bases of perceived exertion. Med. Sci. Sports Exerc. 1982, 14, 377-381. [CrossRef] [PubMed]

26. Rhodes, J.; Mason, B.; Perrat, B.; Smith, M.; Goosey-Tolfrey, V. The validity and reliability of a novel indoor player tracking system for use within wheelchair court sports. J. Sports Sci. 2014, 32, 1639-1647. [CrossRef] [PubMed]

27. Mason, B.S.; Altmann, V.C.; Goosey-Tolfrey, V.L. Understanding the Impact of Trunk and Arm Impairments on Wheelchair Rugby Performance During Competition. Int. J. Sports Physiol. Perform. 2019, 14, 612-619. [CrossRef]

28. Munzel, U.; Brunner, E. Nonparametric methods in multivariate factorial designs. J. Stat. Plan. Inference 2000, 88, 117-132. [CrossRef]

29. Faul, F.; Erdfelder, E.; Lang, A.-G.; Buchner, A. G*Power 3: A flexible statistical power analysis program for the social, behavioral, and biomedical sciences. Behav. Res. Methods 2007, 39, 175-191. [CrossRef]

30. Fast, A. Reflex sweating in patients with spinal cord injury: A review. Arch. Phys. Med. Rehabil. 1977, 58, $435-437$.

31. Trbovich, M.; Ford, A.; Wu, Y.; Koek, W.; Wecht, J.; Kellogg, D. Correlation of neurological level and sweating level of injury in persons with spinal cord injury. J. Spinal Cord. Med. 2021, 44, 902-909. [CrossRef]

32. Kenny, G.P.; Flouris, A.D. 13-The human thermoregulatory system and its response to thermal stress. In Protective Clothing; Wang, F., Gao, C., Eds.; Woodhead, Publishing: Sawston, UK, 2014; pp. 319-365.

33. Croft, L.; Dybrus, S.; Lenton, J.; Goosey-Tolfrey, V. A comparison of the physiological demands of wheelchair basketball and wheelchair tennis. Int. J. Sports Physiol. Perform. 2010, 5, 301-315. [CrossRef] [PubMed]

34. Wecht, J.M.; Harel, N.Y.; Guest, J.; Kirshblum, S.C.; Forrest, G.F.; Bloom, O.; Ovechkin, A.V.; Harkema, S. Cardiovascular Autonomic Dysfunction in Spinal Cord Injury: Epidemiology, Diagnosis, and Management. Semin. Neurol. 2020, 40, 550-559. [CrossRef] [PubMed]

35. van der Slikke, R.M.A.; Berger, M.A.M.; Bergman, D.J.J.; Veeger, H.E.J. To team up or to battle; how do wheelchair court sports compare regarding wheelchair mobility performance? In Proceedings of the RehabMove Congress, Groningen, The Netherlands, 12-14 December 2018. 
36. Button, K.S.; Ioannidis, J.P.; Mokrysz, C.; Nosek, B.A.; Flint, J.; Robinson, E.S.; Munafo, M.R. Power failure: Why small sample size undermines the reliability of neuroscience. Nat. Rev. Neurosci. 2013, 14, 365-376. [CrossRef] [PubMed]

37. Rampinini, E.; Coutts, A.J.; Castagna, C.; Sassi, R.; Impellizzeri, F.M. Variation in top level soccer match performance. Int. J. Sports Med. 2007, 28, 1018-1024. [CrossRef] [PubMed] 